\title{
Les romans publiés à Lyon au XVI siècle, introduction de Pascale Mounier et Mathilde Thorel
}

\section{Michele Mastroianni}

\section{(2) OpenEdition}

\section{Journals}

\section{Edizione digitale}

URL: https://journals.openedition.org/studifrancesi/4628

DOI: 10.4000/studifrancesi.4628

ISSN: 2421-5856

\section{Editore}

Rosenberg \& Sellier

\section{Edizione cartacea}

Data di pubblicazione: 1 avril 2012

Paginazione: 131-132

ISSN: 0039-2944

\section{Notizia bibliografica digitale}

Michele Mastroianni, «Les romans publiés à Lyon au xve siècle, introduction de Pascale Mounier et Mathilde Thorel», Studi Francesi [Online], 166 (I | LVI) | 2012, online dal 30 novembre 2015, consultato il 19 novembre 2021. URL: http://journals.openedition.org/studifrancesi/4628 ; DOI: https://doi.org/ 10.4000/studifrancesi.4628

Questo documento è stato generato automaticamente il 19 novembre 2021.

\section{(c) (i) () $\Theta$}

Studi Francesi è distribuita con Licenza Creative Commons Attribuzione - Non commerciale - Non opere derivate 4.0 Internazionale. 


\title{
Les romans publiés à Lyon au XVI siècle, introduction de Pascale Mounier et Mathilde Thorel
}

\author{
Michele Mastroianni
}

\section{NOTIZIA}

Les romans publiés à Lyon au XVI siècle, introduction de Pascale MOUNIER et Mathilde THOREL, «Réforme, Humanisme, Renaissance», nº 71, 2010, pp. 237.

1 Il 30 gennaio 2010 una tavola rotonda, tenuta a Lione su «Les éditions lyonnaises de romans sous François I Ir ", affrontava il problema della specificità delle presses lionesi per quanto concerne questo tipo di pubblicazioni, ponendo come termini cronologici del periodo da esaminare il 1515 e il 1547. I lavori di questo seminario sono stati prolungati ed estesi all'analisi di un arco cronologico più vasto, giungendo intorno al 1580. Come roman, genere su cui vertono le indagini, viene considerata «une fiction narrative continue qui construit une histoire sur la longue durée». Alcuni dei testi studiati nelle suddette ricerche erano già definiti romans nel Cinquecento, ma anche altri possono essere definiti tali, se li si vuole differenziare dalle raccolte di miti, di racconti o di novelle, dalle cronache storiche o dalle biografie: in tale definizione gioca sicuramente un ruolo la mise en forme degli editori-stampatori. Il bilancio delle ricerche in questione, susseguenti il seminario lionese, è ora offerto dal presente numero speciale di «Réforme, Humanisme, Renaissance», che contiene i seguenti contributi: William KEMP, "Des deux amans" de Piccolomini. Les éditions de la traduction lyonnaise antérieures à 1540 (J. de Vingle, M. Havard, M. Le Noir, O. Arnoullet et D. de Harsy) (pp. 23-33); Michèle CLÉMENT, Co-élaboration à Lyon entre 1532 et 1542: des interventions lyonnaises en réseau sur les 'récits sentimentaux' (pp.35-44); Élise RAJCHENBACH-TELLER, Le "Roland Furieux", Lyon, Sulpice Sabon pour Jean Thelusson, 1543-1544 (pp. 4554); Sergio CAPPELlo, L'édition des romans médiévaux à Lyon dans la première moitié du XVI siècle (pp.55-71); 
Francesco MONTORSI, Le "Guérin Mesquin" traduit par Jehan de Cucharmois 'natif de Lyon', (pp. 73-89); Mathilde thoRel, La "La Pénitence d'amour" (Denis de Harsy, 1537), roman lyonnais? (pp. 91-105); Pascale MOUNIER, Le montage textuel de "Philandre" (1544) et ses rapports avec les "Comptes amoureux" (c. 1542) (pp.107-124); Christine DE BUZON, Le règlement de la lecture des "Amadis de Gaule" à Lyon: quelques épîtres de Gabriel Chappuys, 'traducteur' (pp.125-149); Marie-Claire THOMINE, L'écuyer Girard en habits humanistes: présentation de l'“Hystoire authentique de l'Escuyer Gyrard et de Damoiselle Alyson" imprimée à Lyon en 1545 (pp.151-164); Gilles PoLIzzI, Deux romans 'déguisés' à la Renaissance: le “Chevalier Doré" (1541) et "Gérard d'Euphrate" (1549) (pp. 165-178).

2 Gli articoli che esplorano il vasto campo dell'attività romanzesca a Lione nel Cinquecento hanno come soggetto sia la produzione francese propriamente detta sia la diffusione di versioni, adattamenti o rielaborazioni di opere europee. Le questioni cui si cerca di dare risposta concernono il dinamismo del mercato del romanzo, in termini qualitativi e quantitativi; le tematiche privilegiate dalle scelte editoriali, e le eventuali differenze in questo campo tra Parigi e Lione; le peculiarità, a livello di mise en livre dei testi, delle edizioni lionesi. Il che serve, evidentemente, a ricostruire la 'politica' editoriale di una città, nel nostro caso Lione. 